\title{
Effect of gaboon viper (Bitis gabonica) venom on blood coagulation, platelets, and the fibrinolytic enzyme system
}

\author{
C. D. FORBES, A. G. G. TURPIE, J. C. FERGUSON, G. P. McNICOL, \\ AND A. S. DOUGLAS \\ From Makerere University College Medical School Extension, Nairobi, and the University \\ Department of Medicine, Royal Infirmary, Glasgow
}

SYNOPSIS The action of the venom of the gaboon viper (Bitis gabonica) on blood coagulation, $\stackrel{\omega}{N}$ platelets, and the fibrinolytic enzyme system was studied. The results confirm that the venom of Bitis gabonica has a marked anticoagulant action in vitro. The venom appears to impair clotformation by a direct proteolytic action on fibrinogen, releasing soluble breakdown products.

A bite from a gaboon viper results in severe destruction of local tissue and a systemic haemorrhagic state with bleeding from mucosal and serosal surfaces (Grasset, 1946). The mechanisms by which the venom produces these effects have not been adequately studied but the anticoagulant action has been ascribed to 'fibrinolytic' properties. However, Christensen (1955) failed to find a correlation between the ability of the venom to digest carminestained fibrin and its effect on the clotting mechanism as measured by the recalcification time of plasma.

The purpose of this study was to determine the action of the venom on blood coagulation, platelets, and the fibrinolytic enzyme system.

\section{MATERIALS AND METHODS}

VENOM OF BITIS GABONICA This was collected by $\mathrm{Mr} \mathbf{J}$. Ashe of the Nairobi Snake Park and Mr J. Leakey (Baringo), Kenya, and was dried at room temperature over copper sulphate in a simple desiccator. The desiccated venom was reconstituted in $0.9 \%$ saline to a concentration of $10 \mathrm{mg} / \mathrm{ml}$ and then stored at $-20^{\circ} \mathrm{C}$. The dilutions referred to in the text were made from this stock solution.

Fibrinogen was prepared as described by Biggs and Macfarlane (1962). Plasminogen (grade B) was prepared by A. B. Kabi (Stockholm). Thrombin (Parke Davis) was made up as a stock solution of 100 units $/ \mathrm{ml}$ in $50 \%$ glycerol.

Received for publication 27 August 1968.
PLASMA RECALCIFICATION TIME Various concentrations. of venom were added to this test system (as described by Biggs and Macfarlane, 1962) in place of the saline control.

THROMBIN GENERATION TEST This was performed as described by Biggs and Macfarlane (1962) using whole $\frac{}{\mathbb{Q}}$ blood. Venom was added to one tube and saline as $a$ control to another.

THROMBIN-FIBRINOGEN DILUTION CURVE This was calculated as described by Biggs and Macfarlane (1962).

PROTHROMBIN CONSUMPTION TEST The test was per-त्र formed as described by Merskey (1950). Additions of venom to the blood were made with saline as a control.3.

THROMBIN CLOTTING TIME Venom was incubated with fibrinogen solution and the clotting time of aliquots was followed over the course of 90 minutes and compared? with a saline control (Fletcher, Alkjaersig, and Sherry, 1959).

FIBRINOGENOLYSIS A solution of fibrinogen $(200 \mathrm{mg} / \mathrm{v}$ $100 \mathrm{ml}$ ) was incubated with venom, concentration $0 \cdot 25$ $\mathrm{mg} / \mathrm{ml}$, and aliquots were taken over a 70-minute incubation period. Protein was precipitated with $10 \% \mathrm{~N}$ trichloracetic acid and the soluble products were read ato $280 \mathrm{~m} \mu$ in a spectrophotometer.

THROMBOPLASTIN GENERATION TEST This was carried out as described by Biggs and Douglas (1953). Interference with generation of thromboplastin was tested by adding venom in various concentrations to the standard mixture? with saline as a control. Destruction of formed blood? thromboplastin was tested by generating thromboplastini from the standard mixture, then incubating it with 
venom and testing decay at intervals by adding aliquots to high spun plasma and recording the coagulation time.

ONE-STAGE 'PROTHROMBIN' TIME This was calculated as described by Douglas (1962). Venom or saline $(0 \cdot 1 \mathrm{ml})$, as a control, was added to the test system.

PLATELET AGGREGATION Using the method of Chandler (1958), as modified by Cunningham, McNicol, and Douglas (1965), venom in various concentrations was added to the system and the rate of platelet aggregation compared with a saline control.

ADENOSINE DIPHOSPHATE (ADP) REACTIVITY The ADP reactivity of platelets was measured by the method of Born and Cross (1963). Human platelet-rich plasma was incubated with various concentrations of venom or saline. Adenosine diphosphate in a concentration of $0.5 \mu \mathrm{g} / \mathrm{ml}$ of plasma was then added and the fall in optical density due to platelet aggregation was recorded over 10 minutes.

CASEINOLYTIC ASSAYS These were carried out by the method of Remmert and Cohen (1949) as modified by Alkjaersig (1960). The method is described by McNicol and Douglas (1964). Phosphate buffer $p H 7.6$ and 0.1 molar was substituted for acid and alkali. Results are expressed in casein units per $\mathrm{ml}$. Where venom was used $0.5 \mathrm{ml}$ of a $10 \mathrm{mg}$ per ml solution in $0.9 \%$ saline was substituted for $0.5 \mathrm{ml}$ of buffer.

\section{RESULTS}

PLASMA RECALCIFICATION TIMES The results are shown in Table I. At a final concentration greater

TABLE I

PLASMA RECALCIFICATION TIMES

\begin{tabular}{lllllll}
\hline $\begin{array}{l}\text { Final } \\
\text { concentration } \\
\text { of venom } / \mathrm{ml}\end{array}$ & $8 \mu \mathrm{g}$ & $4 \mu \mathrm{g}$ & $2 \mu \mathrm{g}$ & $1 \mu \mathrm{g}$ & $0.5 \mu \mathrm{g}$ & $0.25 \mu \mathrm{g}$ \\
$\begin{array}{l}\text { Clotting time } \\
(\mathrm{sec})\end{array}$ & $600+$ & $600+$ & 429 & 351 & 227 & 226
\end{tabular}

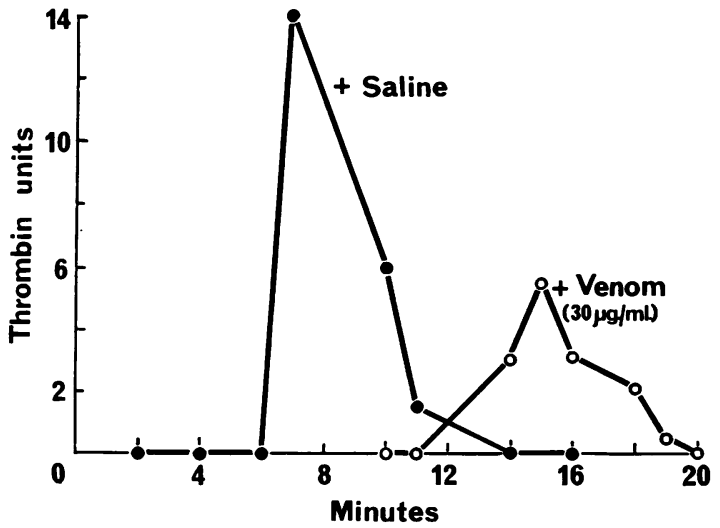

FIG. 1. The delay in thrombin generation in whole blood in the presence of gaboon viper venom.

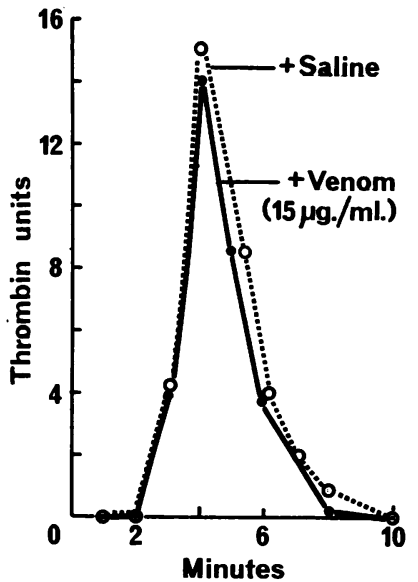

FIG. 2. Thrombin-fibrinogen reaction in the presence of gaboon viper venom.

than $0.5 \mu \mathrm{g} / \mathrm{ml}$ clotting times are prolonged and at concentrations greater than $4 \mu \mathrm{g} / \mathrm{ml}$ the plasma is incoagulable.

THROMBIN GENERATION The results are shown in Figure 1. In the saline control the peak of thrombin generation occurred at seven minutes. When venom in high concentration was added to the incubation mixture no thrombin was formed; however, when the concentration of venom was reduced to $30 \mu \mathrm{g} / \mathrm{ml}$ then thrombin generation occurred but was markedly delayed, the peak occurring at 15 minutes. Thrombin generation was also incomplete as was shown by the further generation of thrombin when brain extract was added to the venom tube at the end of 20 minutes.

PROTHROMBIN CONSUMPTION In the saline control the prothrombin consumption index was less than $5 \%$ whereas in the venom tube, at a final concentration of $40 \mu \mathrm{g}$, the index was $100 \%$.

THROMBIN-FIBRINOGEN REACTION IN THE PRESENCE OF VENOM In order to test the possibility that the venom was interfering with the conversion of fibrinogen to fibrin, thrombin was generated from plasma and aliquots were transferred to two series of tubes, one containing fibrinogen-saline and the other fibrinogen and venom $(15 \mu \mathrm{g} / \mathrm{ml})$. The results are shown in Figure 2. The curves of the coagulation times are identical in both series of tubes, indicating that the venom does not interfere with the conversion of fibrinogen to fibrin under the influence of thrombin.

EFFECTS OF INCUBATION OF FIBRINOGEN AND VENOM In Fig. $3 a$ is seen a gradual prolongation of the 


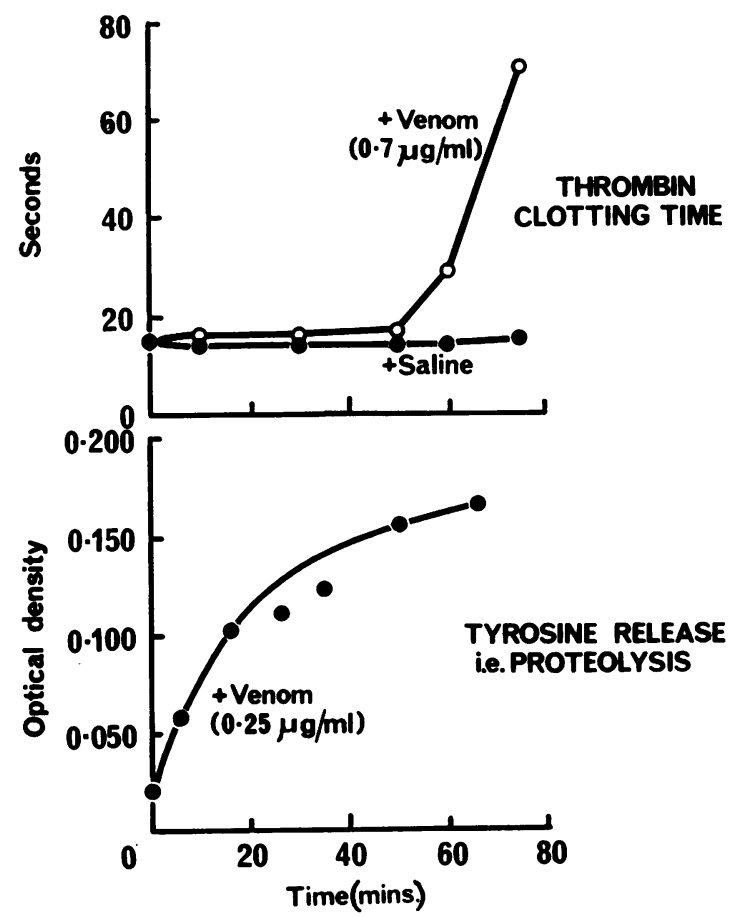

FIG. 3. Incubation of fibrinogen with gaboon viper venom. In FIG. 3a. (above) is shown the prolongation of the clotting time and in FIG. $3 \mathrm{~b}$. (below) the release of soluble products from the mixture.

thrombin clotting time on incubation of the fibrinogen and venom. In Fig. $3 \mathrm{~b}$ is shown the parallel release of soluble products from the venom-fibrinogen mixture.

THROMBOPLASTIN GENERATION TEST Normal thromboplastin production in the saline control is shown in the top curve of Fig. 4, the peak generation occurring at three minutes. In the presence of venom at a concentration of $0.25 \mu \mathrm{g} / \mathrm{ml}$ the amount of thromboplastin activity is diminished. The rate of disappearance of formed thromboplastin was then measured and compared with a saline control. The results are shown in Figure 5. Adding venom to the incubation mixture results in more rapid loss of blood thromboplastin than in the saline control.

ONE-STAGE 'PROTHROMBIN' TIMES The results of adding venom to this test system are shown in Tablef II, which shows that high concentrations of venom? inhibit the tissue thromboplastin system.

TABLE II

ONE-STAGE 'PROTHROMBIN' TIMES WITH ADDITIONS OF

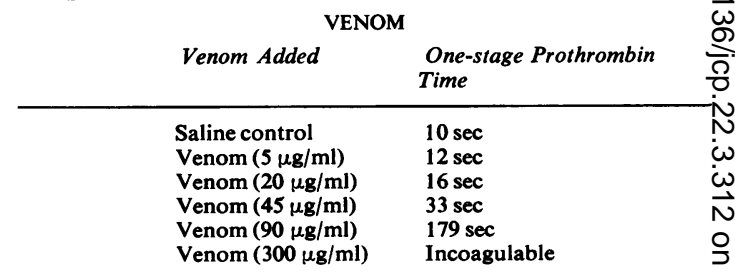

PLATELET AGGREGATION AND THROMBUS FORMATION IN THE CHANDLER TUBE The results of these experiments are shown in Table III. With increasingo concentration of venom, there is a progressive increase in the time for platelets to aggregate and platelets to form a head. At a concentration op $8 \mu \mathrm{g} / \mathrm{ml}$ of venom platelet aggregation is completelys inhibited.

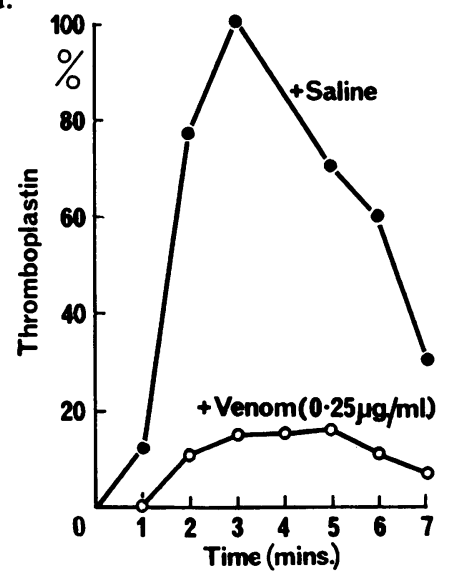

FIG. 4. Thromboplastin generation technique with additio of gaboon viper venom.

TABLE III

EFFECT OF GABOON VIPER VENOM ON AGGREGATION IN THE CHANDLER TUBE

\begin{tabular}{|c|c|c|c|c|c|}
\hline $\begin{array}{l}\text { Plasma } \\
(m l)\end{array}$ & $\begin{array}{l}\text { Normal } \\
\text { Saline } \\
(\mathrm{ml})\end{array}$ & $\begin{array}{c}\text { M/10 Calcium } \\
\text { Chloride }(\mathrm{ml})\end{array}$ & $\begin{array}{l}\text { Venom } \\
(\mu g / m l)\end{array}$ & $\begin{array}{l}\text { Aggregation } \\
\text { (sec) }\end{array}$ & $\begin{array}{l}\text { Platelet } \\
\text { Head } \\
(\mathrm{sec})\end{array}$ \\
\hline $\begin{array}{l}1 \\
1 \\
1 \\
1 \\
1\end{array}$ & $\begin{array}{l}2 \cdot 5 \\
2 \cdot 0 \\
2 \cdot 0 \\
2 \cdot 0 \\
2 \cdot 0\end{array}$ & $\begin{array}{l}1 \\
1 \\
1 \\
1 \\
1\end{array}$ & $\begin{array}{r}0 \\
2 \\
4 \\
8 \\
16\end{array}$ & $\begin{array}{l}285 \\
270 \\
600 \\
\text { Nil at } 1,800 \\
\text { Nil at } 1,800\end{array}$ & $\begin{array}{l}310 \\
290 \\
625\end{array}$ \\
\hline
\end{tabular}




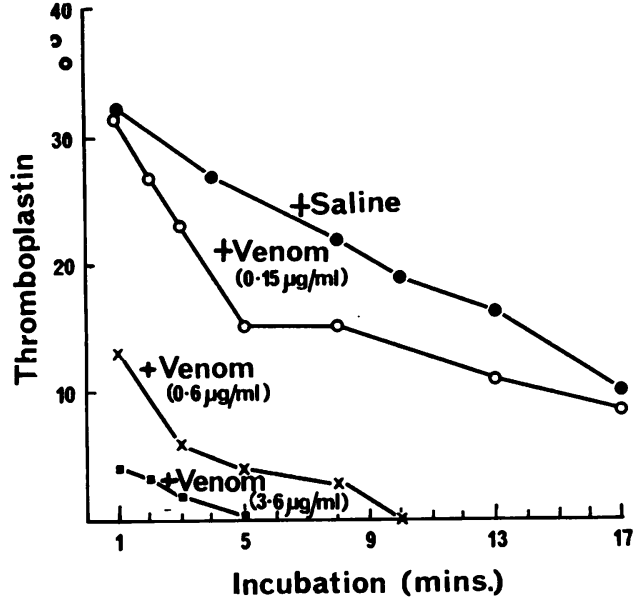

FIG. 5. Destruction of formed blood thromboplastin.

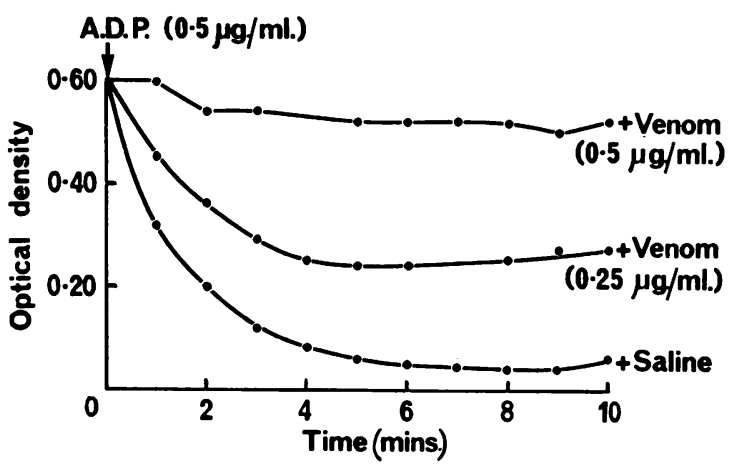

FIG. 6. Effect of gaboon viper venom on platelet aggregation induced by adenosine diphosphate.

ADP-INDUCED PLATELET AGgRegation The lower curve of Fig. 6 shows the rapid platelet aggregation caused by the addition of adenosine diphosphate to the saline control; venom in high concentration inhibits ADP reactivity.

CASEINOLYTIC ASSAYS Results are shown in Table IV which presents for each experiment the mean and standard deviation for seven experiments performed in duplicate. It will be seen that the venom shows direct caseinolytic activity $(1 \cdot 1 \pm 0 \cdot 2$ units of activity): the venom, however, does not activate plasminogen.

TABLE IV

CASEINOLYTIC ASSAYS

$\begin{array}{ll}\text { Venom alone } & 1 \cdot 1 \pm 0 \cdot 2 \text { casein units } \\ \text { Plasminogen + venom } & 2 \cdot 1 \pm 0 \cdot 2 \text { casein units } \\ \text { Plasminogen alone } & 0.9 \pm 0 \cdot 2 \text { casein units }\end{array}$

\section{DISCUSSION}

The results confirm that the venom of Bitis gabonica has a striking anticoagulant action in vitro. The overall anticoagulant action, as reflected in the plasma recalcification time, is a summation of actions of the venom on the coagulation mechanism at several levels. Interference with the blood thromboplastin system in the presence of the venom was demonstrated by defective thrombin generation, defective prothrombin consumption, and, more specifically, by inhibition of thromboplastin generation and accelerated loss of formed thromboplastin.

The coagulation defect is compounded by inhibition of the tissue thromboplastin system and inhibition of platelet aggregation, as demonstrated in the Chandler tube technique and in ADP-induced platelet aggregation. Further, although the venom does not seem to have a direct effect on the thrombinfibrinogen reaction when incubated with fibrinogen, it progressively impairs clot formation by a direct proteolytic action on fibrinogen with release of soluble fibrinogen breakdown products. These may be expected to produce defective fibrin polymerization, the presumed explanation of the prolonged thrombin clotting time (Fletcher, Alkjaersig, and Sherry, 1962). This last mechanism may be of considerable importance in vivo when after snake bite venom and fibrinogen may be in prolonged contact in the circulation.

Despite the proteolytic activity of the venom, no activation of plasminogen could be shown.

Grasset and Zoutendyk (1938) report that the average yield of venom per gaboon viper is in the region of $200 \mathrm{mg}$ and up to $484 \mathrm{mg}$ has been obtained from one specimen. Assuming that all the venom is injected in the bite the level of venom in the plasma of a man weighing $70 \mathrm{~kg}$ could theoretically be $60 \mu \mathrm{g}$ per ml of plasma. This would be sufficient to produce a severe haemostatic defect.

If the venom fraction which produces this anticoagulant effect can be isolated then it may have a place therapeutically in the prevention of platelet aggregation and fibrin deposition; fractionation studies are now in progress.

We are grateful to $\mathrm{Mr}$ J. Ashe, Nairobi Snake Park and Mr J. Leakey (Baringo) for provision of the venom.

Financial assistance was provided by the Kenya Ministry of Health, East African Medical Research Foundation, Ministry of Overseas Development, Hoechst (East Africa) Limited (D. A. Jayne, Esq); Organon Laboratories Limited (Dr C. L. Hewett); G. D. Searle and Company Limited (Dr G. R. Venning); Boehringer Ingelheim Limited (Dr D. A. Middleton); Pfizer Tropical Research Laboratory (Dr G. C. Gould); The Pfizer Corporation (Dr J. R. Tishler); and ICI Pharmaceutical Division. 
Reagents were provided by Abbott Laboratories Limited, Illinois, United States of America, and by A. B. Kabi, Stockholm, Sweden.

\section{REFERENCES}

Alkjaersig, N. (1960). In NIH Conference on Thrombolytic Agents, edited by H. R. Roberts, and J. D. Geraty, p. 316. Chapel Hill.

Biggs, R., and Douglas, A. S. (1953). J. clin. Path., 6, 23.

Biggs, R., and Macfarlane, R. G. (1962). Human Blood Coagulation and Its Disorders, 3rd ed. Blackwell, Oxford.

Born, G. V. R., and Cross, M. J. (1963). J. Physiol. (Lond.), 168, 178 Chandler, A. B. (1958). Lab. Invest., 7, 110.
Christensen, P. A. (1955). South African Snake Venoms and Antivenoms, The South African Institute for Medical Research,으 Johannesburg.

Cunningham, G. M., McNicol, G. P., and Douglas, A. S. (1965). Lancet, 1, 729.

Douglas, A. S. (1962). Anticoagulant Therapy. Blackwell, Oxford.

Fletcher, A. P., Alkjaersig, N., and Sherry, S. (1959). J. clin. Invest. 38, 1096.

(1962). Ibid., 41, 896.

Grasset, E. (1946). Acta trop. (Basel), 3, 97. , and Zoutendyk, A. (1938). Trans. roy. Soc. trop. Med. Hyg., 31,

McNicol, G. P., and Douglas, A. S. (1964). Recent Advances in Clinical Pathology, Series IV, edited by S. C. Dyke, p. 187. Churchill, London.

Merskey, C. (1950). J. clin. Path., 3, 130.

Remmert, L. F., and Cohen, P. P. (1949). J. biol. Chem., 181, 431. 